\title{
Reflections on a global agenda: on variety, fragmentation, change, and the big questions ahead
}

\author{
Jeroen Huisman and Marijk van der Wende
}

\section{Setting the scene}

Our point of departure in writing this book has been a twofold ambition. First, to cover a broad range of aspects relevant in higher education research, while paying specific attention to the changing global context. Second, to produce a book relevant for a global readership and stimulating higher education research globally. In line with the series' spirit we set out to explore the higher education research space in provocative ways, map out the potential directions of travel, being relevant but visionary, forward-looking and innovative. In that sense, we deliberately intended to deviate from what could be termed the "classical approach." That classical approach - recognizable in many journal articles and book chapters - evolves along basic steps of scholarly inquiry: what do we know, what are the gaps in our scholarly understanding, which theory and methods are well-suited to fill these gaps, what are the results of such an investigation and what has this contributed to our academic understanding of the phenomenon investigated. The approach in this book has been slightly different. We invited our contributors to think beyond the classical approach. We hasten to say that there is nothing inherently wrong with the classical perspective, but it keeps scholars largely within their comfort zone by building - in most cases gradually - on what we know and, importantly, it does not challenge our underlying assumptions about the phenomenon at stake. We therefore posed the general question what recent and contemporary (and possibly near future) changes in the global context of higher education mean for research in our field. More specifically, we invited authors to pay attention to the COVID-19 pandemic as an unexpected "global experiment," but also as an opportunity to rethink existing theories against a completely new set of data, which could shed a new light on existing themes. In other words, we 
invited authors to consider what these changes imply for a higher education research agenda in terms of emerging and new research questions, changing paradigms, and to contemplate to what extent the changes are challenging our main assumptions.

This general idea has been translated in a set of guidelines for authors. We envisaged that each chapter should include:

- An argument/rationale for the relevance of the chosen theme (topic/focus) with a particular view to the changing global context.

- An explicit account of the disciplinary or interdisciplinary perspective chosen.

- A comprehensive but compact state of the art overview of research undertaken and critical assessment in terms of its empirical, theoretical and methodological aspects.

- Resulting in proposals: what does this imply for the research agenda in terms of emerging and new research questions, what needs or can be done, and how (e.g. theories and methods)?

- To what extent, why and how, are our main assumptions being challenged, are we urged to change paradigms, seek new (inter)disciplinary approaches?

In our search for contributors we followed two strategies. We invited authors from our extensive network to write a chapter on their area of expertise, but also disseminated our call more broadly through learned societies like the Society for Research into Higher Education, the Consortium for Higher Education Researchers, the Association for the Study of Higher Education and to the Consortium for Higher Education Research in Asia. We also made use of a number of listservs to disseminate our call to disciplinary groups in political sciences, education and sociology. In this way, we reached out to a large variety of scholars with different disciplinary backgrounds, levels of expertise, levels of seniority and geographical location.

We aimed to be relevant for a global readership, thus seeking contributions from around the world, aiming to be thematically and globally relevant rather than being country-specific. Chapters should be organized in a thematic fashion rather than adhering to a comparative framework. Looking at the final set of chapters included in the volume, we think we succeeded in grasping the geographical variety, with chapters from authors residing in Australia, France, South Africa, Japan, the UK, the Netherlands, Belgium, Portugal, Norway, Poland, Azerbaijan, Italy, Poland and Chile. Developments in important systems such as the US and China are taken into account in various contri- 
butions. We are also pleased to see quite some diversity in terms of level of seniority of authors and disciplinary background. It does not surprise that most contributors are from the social and behavioral sciences; this reflects what other researchers (Teichler, 2000; Tight, 2013) have previously noted as well. Within these two disciplinary groups there is still some variety, with authors building on insights from the political sciences, public administration, economics, science studies, sociology/anthropology, educational studies and psychology. That said, there are clear lacunae, with the humanities (history, philosophy, cultural studies) being almost absent (see also Clark, 1984).

\section{Celebrating diversity or lost in fragmentation?}

Without doubt, the variety we found is reason for celebration. Apparently, there are many interesting higher education themes to investigate. The growth of our field (Tight, 2018) fits in with that idea: there are more journals, their page budgets increase and there is increasing specialization. That level of specialization is often seen as a positive. For sure, if sizeable groups of researchers focus on a specific sub-theme, there are, generally speaking, positive expectations about what this implies for increasing the "stock of knowledge" on that particular theme. The downside, however, must also be acknowledged. From bibliometric research and network analyses we also learn that too strong specialization may inhibit innovation and knowledge production (see for a reflection on higher education, Vlegels and Huisman, 2020). Also others have expressed their concerns about fragmentation (Macfarlane, 2012, Daenekindt and Huisman, 2020; Horta and Jung, 2014), using the metaphors of silos and archipelagos.

Our invitation explicitly stated that "Global Higher Education" should not be limited to higher education's global features, globalization, internationalization, or transnational higher education. A globally relevant book should rather aim to cover all themes that are globally relevant, that is, the field of higher education research at large, including work focusing on micro (teaching and learning), meso (organizational), and macro (system) levels, by attracting contributions from a broad range of disciplines, including interdisciplinary approaches. Although the book obviously could not cover all relevant and interesting themes, we think we have captured an adequate breadth of our research field. Figure 1.1 exemplifies the potential variety of themes by two dimensions: discipline and level of analysis. Whereas the sciences on the left side are only represented by science and technology studies (in Chapter 8 by Cloete et al.), the social and behavioral sciences are omnipresent: econom- 
ics, political sciences, organization studies, sociology, public administration, psychology, educational sciences, while the humanities play a quite modest role. The chapters cover a good variety of the themes and levels of analysis as presented in Figure 1.1, yet tend to cluster around the center, thus confirming the general picture of the higher education research field as presented above.

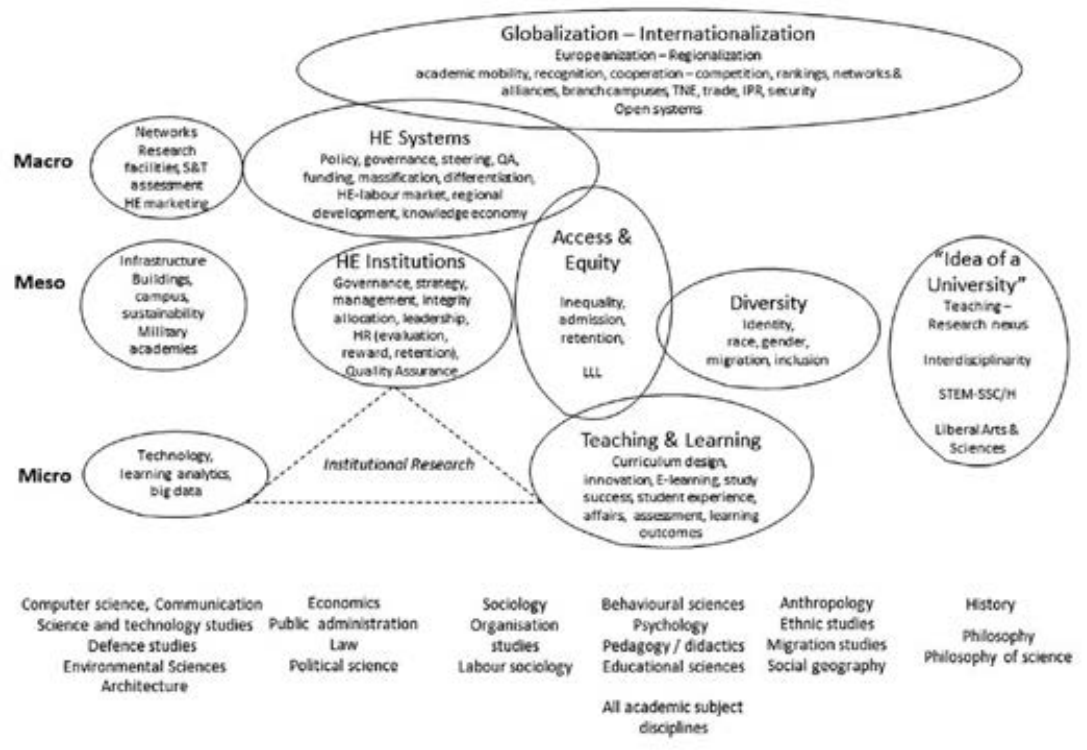

Source: van der Wende (2020).

Figure 1.1 Higher education research: mapping the field

This volume demonstrates both coherence and fragmentation. Coherence is shown in the recognition by most authors that higher education systems and their institutions cannot be conceptualized and analyzed in (national) isolation anymore. Many attest to the idea of open systems, global influences, cross-border movements and the increasing importance of internationalization. At the same time, fragmentation is reflected in that they seem to speak quite different languages and tend to use different concepts and theories. We found it striking to see that authors refer to quite different literatures (see the references for each chapter) and that in some cases the overlap was limited to only a couple of books that address generic topics or broad themes in our field. Fragmentation may concern higher education as the object of study, but also globalization, regionalization and internationalization as contextual factors affecting it. If this applies indeed to both object and context and consequently 
to their relationship this could further weaken the already fragile common body of knowledge in our field and could thus be seen as a worrying development. Even more so when (geo)political tensions in its context are on the rise and risk becoming included as normative positions rather than making different but coherent theoretical and methodological choices. Without assuming that anything in higher education is global, let alone universal, per se, this would at least hinder a constructive global dialogue on higher education and its research agenda.

The above reflections on fragmentation should not be seen as a lament. As said, we appreciate variety and specialization, but are at the same time somewhat worried about the lack of bridges being built between different themes (see also Daenekindt and Huisman, 2020) and a lack of a common language and solid bedrock. Maybe we should accept that our field will unlikely reach the status of a discipline (see Tight, 2020 for a recent reflection) and accept that researchers have different motivations and inspirations to engage with higher education as a theme for research. But more attention to "connecting the dots" is necessary. This will be fruitful for innovative thinking and broadening the knowledge base, but it is also important in light of our task - as higher education researchers - to contribute to solving problems in policy and practice, relevant for the national context and preferably beyond that at the global level. As a thought experiment: imagine that - similar to virologists across the globe recently being challenged to find solutions to the pandemic asap - higher education scholars were asked to solve a set of wicked problems regarding higher education (funding, quality, access and equity) in the relatively short term. How would they fare? And, importantly, how would practitioners and policy-makers respond to the myriad of "solutions" offered, each written in a different scholarly language, with different points of departure, partly theoretical and perhaps ideological, and - highly problematic - contrasting and contradicting findings?

We do not have a clear and straightforward solution at hand, but awareness of our vulnerable position as a community of higher education researchers may be a good first step. The richness of the variety demonstrated in this book, as well as in many other volumes, can only bear fruit if borders are being crossed. Clearly, this also refers to discussions about interdisciplinarity, as most global challenges are known to need more than one discipline to find adequate solutions. With the increasing level of specialization and expanding number of specialized journals as discussed above in mind, connecting the dots may actually require, above and beyond awareness, the genuine curiosity, open mind, and intellectual courage to cross borders, instead of creating new ones. 


\section{Theory and method}

The need to cross and extend existing borders sheds light on the use of theory and method and brings us to reflect on the "toolbox" needed to tackle emerging and new research questions. The contributions in this volume confirm - and this is also a consequence of our explicit call - that thematic interests in our field prevail (Macfarlane, 2012). The choice of research designs and methods often play a serving role. This is an acceptable position, but it does raise the question of what would be the most appropriate research designs and methodologies to answer key research questions. In the book chapters there is a strong reliance on what could be termed traditional research designs and (often qualitative) methods. This prompts us to call for a revitalization of the debate on research designs and methods. This should not be a discussion that brings us back to the dogmatic stances on whether quantitative research is better (or not) than qualitative research, but a sophisticated exploration is needed of what are the best - as in fitness-for-purpose - instruments to answer specific questions. And this debate includes keeping an open mind towards new developments in the social sciences and beyond (e.g. dealing with big data, using artificial intelligence and data visualization).

Regarding the use of and reference to theory, we noted that authors showed a high level of conceptual engagement fitting with the idea of addressing key themes in higher education research. It begs, however, the question of how we go about the use of theory in our field. Following Lewin's $(1945,129)$ adage that there is "nothing so practical as good theory," we would - on the one hand - advocate much more engagement with theories developed within the disciplines that feed our field. This would also strengthen the potential of our research to infuse discipline-based theories. Decades ago, research on higher education was highly influential on the disciplines (see e.g. Elken and Vukasovic, 2019). On the other hand, theoretical engagement should not be seen as a mantra. Accepting that our field is problem-driven (Teichler, 2000), it is understood that problems, themes, ideas and concepts constitute the research agenda, with theoretical and methodological choices possibly being second order. Yet as noted above, we should be aware of safeguarding or (re) building sufficient common ground to allow for a constructive global dialogue on higher education and its research agenda. 


\section{What is a research agenda?}

We also learned that the concept of a research agenda, as such - let alone a global one - cannot be assumed that easily. Among our contributors, there was no consensus on what would constitute a research agenda. Our initial, and likely somewhat implicit, idea was that a research agenda should be a plan that focuses on issues and ideas (on a particular theme in our field). We further offered the contributors prompts regarding the what and how, with attention to emerging and new research questions, what needs or can be done, and how (e.g. which theories and methods would be needed to answer these questions).

Not surprisingly - see also our reflections in the previous section - authors responded to the call in quite different ways. In the proposed research agendas, we see undertones of advocacy, with authors "defending" the themes discussed as being of (crucial) importance, which resonates with our earlier contemplation on the level of specialization in our field. Obviously, authors' passion may spark the interest of the reader and we think the contributors have been successful in inspiring the reader. But there is a fine line between enthusiasm and dogmatic advocacy, the latter running the risk of contribution to the maintenance of the fragmentation in our field. Another dimension in research agendas relates to the difference between "going deeper" and "going beyond." We would argue that "going deeper" is particularly relevant for areas that have been investigated at length and the developed body of knowledge allows for asking more specific - and possibly smaller - questions, but warn against research staying in the comfort zone (see first section of this chapter). It remains important to "go beyond" by looking at existing or new phenomena from different angles and particularly to see the specific themes we research in a broader context (see our earlier remarks on "connecting the dots"). We feel the latter is also of crucial importance to contribute - as higher education researchers - to policy and practice.

\section{Putting change in perspective: on higher education's "rapidly changing global context"}

Besides our aim for a globally relevant account on and agenda for higher education research, we set out to pay particular attention to the current dramatically changing global context; what will the COVID-19 pandemic, during which this book was being drafted, imply for higher education and how can that be understood in terms of new research questions? [How] will this affect 
the existing paradigms or even challenge our main assumptions? Can this already be reflected in the research agenda, or is it still too early to imagine the long-term effects of this unexpected "global experiment"? Many of our authors observe unimagined change indeed, from which much can be learned. But how much do we know at this point about the extent to which these changes are (ir) reversable and the lessons-learned sustainable? Yet some things are becoming quite clear already. First, we have learned to put "dramatic change" into perspective. Second, we realize that we must learn to live with uncertainty. These two broad notions deserve some reflection and will be discussed in this section, thus providing a framework for the thematic chapters to follow.

We all remember how quite many books and articles on higher education used to start with sweeping statements on higher education's "rapidly changing environment" or even "ever faster change" as its context. But what was this actually based on? According to Dorling (2020) mostly on the "great acceleration," that is, the speedy increase in economic growth, productivity, fertility, and so on as spurred by technological innovation, which was witnessed during the past five generations. Higher education was at the heart of it with massification of student enrolment and a boosted production of scientific knowledge. But that period is now behind us, he argues. Evidence on the slowdown in the actual amount of change over the last decades is abundant, as he demonstrates with rich statistical data series that show decelerating change in most areas, notably in demography (fertility rates, life expectancy) and economic growth (GDP per person), but with the rise of global temperature as the catastrophic exception. Thus and contrary to the advocacy for "constant change" or "disruptive change" by change gurus in and around higher education, Dorling postulates that we have been living through an anomaly during the great acceleration and that with the end of it, as evidenced by the slowdown, we already entered a phase towards a new stability.

The usual clichés on "the dramatically changing" environment of higher education were further and then most thoroughly relativized by the outbreak of the COVID-19 pandemic in early 2020. It is identified in Chapter 9 by Law and Locke as "an exogenous factor that is rapidly reshuffling the relatively stable environment of higher education in a way that could have a long-lasting, profound impact." Their acknowledgment of the previous "relatively stable environment" could be seen as in line with Dorling, but rather seems to stem from the perspective of the unexpected and massive global change caused by the pandemic. Relative stability as compared to what came as a complete surprise, including the uncertainties about its long-term impact. What adjustments will be required of higher education, what further challenges are in store for the sector? 


\section{The impact of COVID-19 on higher education}

We can look in many directions when seeking for answers or anchors to the questions on the impact of the COVID-19 pandemic. Historian and futurologist Harari (2020) points to two major choices. The first relates to the temporary surveillance measures and trust in scientific health data, which may become permanent and come at the expense of citizens' rights and freedom. The second regards nationalist isolation (for instance regarding vaccine dissemination) as a threat to global solidarity. However, the pandemic itself and the resulting crisis are global problems, he argues, that can only be solved by global cooperation.

Universities delivered the ultimate proof of value of cooperation in an open global science system. The genomic sequence of the virus was quickly detected and globally shared, allowing COVID-19 vaccines to be developed at unprecedented speed. An avalanche of further research on the pandemic was launched with immediate funding made available by institutional, national, and international sources. At the same time and despite closed campuses and borders, universities mostly managed to continue teaching by quickly switching to online education. Chapter 10 by Donina and Antonowicz analyses how the crisis and consequent radical external changes affected the internal organization of universities and how their potential long-term impact can be studied. Chapter 11 by Hilliger and Pérez-Sanagustín discusses how the variations in reach and effectiveness of online education may account for increased inequality and underline the quality of digital infrastructure as a crucial condition for global learning opportunities in a digital age.

Harari's concerns are reflected in the higher education debate, for instance around the (mis)use of proctoring software for student assessment, of student data for learning analytics, research on artificial intelligence and dual-use technologies which may hamper human rights, and are reflected in accusations of espionage, and visa restrictions to students and researchers from particular countries. In return, universities, while faced with the challenges of the pandemic, speeding digitalization, and rising nationalism, stand firm to defend their values, academic freedom, institutional autonomy, global cooperation, open science, and take the lead in jointly developing global ethical standards for research and finding avenues towards "digital humanism." Universities showed adaptability and have proven to be resilient, hopefully a basis strong enough to deal with further challenges and uncertainties ahead. 
And there will be. According to Chomsky (2019), beyond the pandemic, higher education would need to be prepared for what, in his view, may be the three most important existential threats to humanity: global warming, nuclear war, and a deteriorating democracy. In his view "Internationalism and an engaged and educated population are the only hope for dealing with these major crises." It is feasible, he says, but requires "A society that is not only educated, but able to deliberate, to interact, globally in fact, to move towards solutions" (Chomsky, 2020). Realizing that it is not enough to have just the knowledge, because engagement also implies international solidarity. Educating the next generations in this spirit is probably the greatest challenge for higher education to face.

In fact, this implies a formidable task for higher education. Preparing students for a global future means finding avenues to support them in developing the abilities most needed in order to generate the efforts required to tackle these global challenges in an increasingly nationalist and antagonistic political climate. How do we help students finding nuance, intellectual humility, understanding the validity of other perspectives, overcoming value judgments, national(ist) lenses, approaching big questions and ethical issues from different perspectives, that is, to develop empathy? Arguably this requires universities to move beyond the current internationalization-as-an-industry kind of model. It goes without saying that these aims can best be achieved in an open higher education environment, allowing actual interaction and mutual learning between students and faculty from different backgrounds (van der Wende, 2017; 2021).

Useful insights from research on global citizenship education are presented in Chapter 12 by Pownall, Harris, and Blundell-Birtill, who underline that the concept needs to be embedded in university curricula, rather than be an add-on option for internationalization. This view deserves further research evidence from across the boundaries of social sciences and humanities into the STEM fields. Do we sufficiently understand the different internationalization pathways across the disciplines, or is higher education research hindered by disciplinary bias as it is mostly performed by social scientists (as also ascertained above)? What is the role of the humanities, as the disciplines most concerned with the human mind, but more often defined by national or regional frames, or even a prime object of regional or nationalist agendas (Sachsenmaier, 2020)? How does this compare to the STEM disciplines in which by far the most international collaboration takes place and how can these different dynamics be explained to better understand internationalization in the university at large? Understanding the long-term impact of COVID-19 on universities requires a closer focus on how the already quite different dynamics across the 
STEM - social sciences - humanities spectrum will be affected. How will likely even stronger funding support for STEM impact institutional cohesion, that is, the crucial connection between the "Two Cultures" and the teaching-research nexus? How will it affect the position of comprehensive as compared to technological universities? Which parts of the disciplinary spectrum will be more or less global in their orientation and operations and (thus) more/less likely to contribute to tackling global challenges and shaping a renewed internationalization agenda?

Chapter 7 by Aghayeva highlights the need for new ways of international academic mobility that are more sustainable ("green") and socially inclusive. Research on non-traditional and informal types of mobility could avoid the focus on elite cosmopolitanism often inherent to the traditional and more formal types. It opens up to wider questions on internationalization, which has become an important dimension of higher education, but is it up to the challenges ahead as sketched above? How could it contribute to Chomsky's call for "progressive internationalism"?

\section{Open systems and the university's role in society}

Whether the necessary condition of system openness can be sustained, is questioned in Chapter 2 by van der Wende. Under the current circumstances, referring again to the rise of nationalism and geo-political tensions, it is even uncertain to what extent the current mechanism of free mobility within the EU will be sustainable and how the EU's open policy for higher education and research can be upheld in the broader global context.

Given the changing patterns of globalization, where the center of gravity seems to be shifting from the West to the East, the question is not only how open systems could be better regulated (balanced), but also whether global convergence can or should still be taken as the assumed direction and outcome. In other words; whether "global higher education" as such can or should be assumed at all, if it has ever really emerged (van Damme and van der Wende, 2018). This would of course have serious implications for the research agenda. While on the one hand "methodological nationalism" tends to empirically hide the global dynamics across national systems (see Chapter 2), "normative globalism," on the other, may hinder a full understanding of the differences, synergies and tensions between the global and national systems (Marginson, 2021). 
The interruption of global transportation and supply chains, as caused by the pandemic, are fueling the return of economic isolationism (US), "strategic autonomy" (EU), and feeds into Eastern regionalization (e.g. the Shanghai Cooperation Organization ${ }^{3}$ and the Regional Comprehensive Economic Partnership ${ }^{4}$ ), as an important alternative. Interestingly, however, also in this context integration or convergence cannot and should not be the only expected outcome, as is illustrated for the EU in Chapter 6 by Veiga. Pointing to perhaps a bias in prior research, she widens the perspective to include differentiated integration and actual disintegration (e.g. Brexit), as alternative theses or lenses to be taken into account. In doing so, she opens up an interesting and relevant literature and provides analytical tools for researchers to better understand counterforces and trends when studying these processes. Convergence or divergence thus continues to be one of the main questions both at global and regional levels, concerning not only system characteristics, but also the related governance models and arrangements. Chapter 3 by Huisman and Huang suggests no final answer, since despite active policy borrowing and transfer across systems, actual implementation and change is always defined by domestic context's considerations. It could thus simply be concluded that also for higher education it goes that: "All politics is local."

Yet we should look further and need to be aware of what is really at stake; what are the forces that are driving the values which underpin the role of higher education in society, its free and independent role in providing a global common good, with academic freedom and institutional autonomy as its crucial elements? It seems that under the foremost Western (neo-liberal) globalization paradigm, which became dominant after the fall of the Berlin Wall, these values and related freedoms have been taken for granted, but now seem to be diverging under the influence of less liberal influences from within Europe and beyond. Combined with and further challenged by a digital revolution which potentially brings universities more under the control of surveillance states and surveillance capitalism (see Chapter 2), both lacking appropriate democratic legitimacy and risking to jeopardize academic freedom and institutional autonomy.

This leads back to Harari's two major choices and also presents the key questions for higher education in the period ahead: will it remain globally connected, committed to delivering a common good, to its global mission of contributing to SDGs, and up to the heavy task, as sketched by Chomsky, of educating students to be able and sufficiently engaged to actually deliver on these goals? 


\section{Global rebalancing and the big questions ahead for higher education}

It is too early to assess the full impact of the COVID-19 pandemic and, partly related to that, the shifting geo-politics on higher education globally. The pandemic is proving to be a test of solidarity at all levels and the situation is still fragile. Are we returning to a bi-polar or moving towards a multi-polar world? Multilateralism would need to be redefined, involving more and better the countries formerly known as "developing," some of which have for long been insufficiently included in the global dialogue and governance of international institutions, as compared to their enormous growth and progress. China is making its way into these negotiations and institutions with great determination, but as indicated in Chapter 8 by Cloete et al., it is in fact Africa which will display the greatest demographic growth in the decades ahead, likely hosting the largest student and young labor populations by the mid-century. This renegotiation and rebalancing process will likely result in new conditions for higher education globally, for international collaboration in particular, and an agenda that can no longer ignore Africa as has often been the case.

The future of open science and global collaboration seems ambiguous. A range of questions are unanswered as yet. How will global collaboration and competition be (re)balanced? Will the higher education context remain as open as needed for both mechanisms to produce the so desired global common good? Or is the era for global higher education and open science (really) over? (How) can digital technology compensate for growing barriers and physical limitations? Will the Internet remain global or further fragment into regional or even national versions (i.e. "Splinternet")? Will digital technology remain human enough to avoid all intelligence to become artificial?

Higher education cannot sit back and wait for answers. It will be expected to lead, rather than be a follower. Universities are urged to rethink internationalization, the nature of their international partnerships, and the academic values they stand to defend. What will this imply for university leadership, for managing uncertainty, strategic planning, scenario building, and for investment strategies? Research thus needs to inquire the developments in both the regulatory and the normative aspects of governance; how can European and international law support higher education collaboration? How can it be sustained under conditions of increasing security risks, but without jeopardizing institutional autonomy, academic freedom, or infringing human rights? How open can it be? 
The aim of this chapter is not to be alarmist, yet these may be just some of the big questions that lie ahead. Universities are known to be great survivors thanks to their adaptability and have proven their resilience again during the COVID crisis. But the pandemic also brought to the surface and amplified already emerging trends which deserve a place on the research agenda.

First and probably most discussed is increased inequality. It is well-noted that socio-economic (more precisely income) inequality globally decreased during the last decade mostly due to China's growth, but increased within (mostly) Western countries (Milanovic, 2016). Decreasing global inequality was also observed in higher education, with more countries moving towards knowledge economies, increased intraregional cooperation, and student numbers exploding globally (UNESCO, 2015). However, in the wake of the global financial (2007-08) and ensuing euro crisis (2009-11), public financial support for higher education became under pressure in many Western countries and the Anglo-American model with high private contributions became increasingly criticized for issues of equity and decreasing value for money. Mounting student debt in relation to growing proportions of graduates taking non-graduate jobs, and more jobs likely to be replaced by automatization, robotization, and the application of artificial intelligence, calls the costs, relevance, and the meritocratic role of higher education into question.

Stiglitz noted in the fall of 2020: "Unfortunately, as bad as inequality had been before the pandemic, and as forcefully as the pandemic has exposed the inequalities in our society, the post-pandemic world could experience even greater inequalities unless governments do something." And almost halfway into 2021 it is clear that they do indeed. "The State is back" with a magnitude of post-crisis investment, unseen since the post-World War II Marshall Plan. Unlike the quite uneven austerity versus investment measures for higher education in packages after the financial crisis, the multi-annual post-COVID recovery budgets in the US, the EU, and China all seem to include investment in higher education and notably research. Yet no Western country seems to be able to parallel the domestic investments made by China, which recovered also economically faster from the pandemic. Meanwhile it is unclear when and how the Global South will recover and (thus) how the global inequality picture will eventually turn out, how this will affect the Sustainable Development Goals, and higher education's expected contribution to these. What will the "Return of the State" with all its public investment imply for the socio-economic role of higher education, for its governance, the role (and mix) of stakeholders, autonomy and accountability? Will higher education be nationally re-rooted? 
To what extent will digital technology help to rebalance inequality? Recovery packages propose a big roll-out of digital infrastructure, with the potential to create equal learning opportunities globally. Chapter 11 highlights not only the essential role of connectedness through digital infrastructure, but also the need to build a shared understanding and expertise on how digital data can be used for continuous curriculum improvement by using learning and curriculum analytics. Will digital solutions compensate for the high costs of traditional academic mobility, as discussed in Chapter 7? All of this has been promised before, but will the COVID crisis make the technology push happen after all? Or will higher education return to or blend it into the traditional cottage-industry type practices and techniques? The latter option holds the risk of increasing costs (IT as an add-on), while the big question is: will these changes contribute to stabilizing or reducing the costs of higher education? Chapter 4 by Roy clearly shows the problem of the ever-rising costs, or higher education's "cost disease." In relation to growing private debt, uneven and increasingly uncertain outcomes in terms of job opportunities, this is feeding doubts about the value of a higher education degree in Western societies, while it is still highly valued in emerging economies. Will the use of digital technology, more and better cooperation between higher education institutions contribute to more efficiency, that is, reduce costs per unit of instruction, while maintaining or increasing quality, and equalize opportunity globally?

How to avoid undermining the meritocratic ideal by further dividing winners and losers between those who can afford the costs of higher education (and of admission as such), as observed by Sandel (2020)? Mostly in the US, where in his view, and framed by the neo-liberal globalization of the time, higher education itself has become a cause of rising inequality, putting social cohesion and eventually democracy at risk. "Colleges and universities preside over the system by which modern societies allocate opportunity. They allocate the credentials that determine access to high-paying and prestigious positions. For higher education, that role is a mixed blessing" (pp. 155-156). Not only would the "credentialist prejudice" (i.e. disdain for the less educated) undermine the dignity of work, as argued by Sandel, in many cases, and beyond the elite institutions, it may in fact only train students for middle-income jobs that have been largely offshored or made precarious (Newfield, 2021). Thus, while in Western societies higher education's value, relevance, and merit as such are being called into question, countries in Asia (notably India and China), Africa and Latin America already face a large, or anticipate a further growing, middle class hungry for higher qualifications.

Growth and decline represent major aspects of the change ahead. Asia and Africa will together constitute over three quarters of the world's population 
in 2050, reducing the North American and European share together to less than one fifth. Only one quarter of the global middle class will live in OECD countries by 2030 .

This gets us back to Dorling's "slowdown" thesis presented above. How will higher education in the West transfer after decades of growth (massification) to absorb and adjust to decline? Meanwhile higher education systems in other world regions will not only expand, but also reach global excellence and world status. The likely most significant consequence is to accept that we need to move beyond a Western perspective on global higher education, and to adjust higher education research - agenda, theories and methods - to that new reality.

We hope that this book will be a stepping stone in this process, stimulating global collaboration, progress, and innovation in the concepts, theories, and methods used in this field of research. And we hope that higher education's future will be global indeed.

\section{Notes}

1. The Digital Humanism Initiative, see: DIGHUM - Digital Humanism (tuwien. ac.at).

2. This refers to C.P. Snow's famous "Two Cultures" essay (1959), in which he lamented the great cultural divide that separates two great areas of human intellectual activity, "science" and "the arts." Snow argued that practitioners in both areas should build bridges, to further the progress of human knowledge and to benefit society.

3. Shanghai Cooperation Organisation (SCO) is a Eurasian political-economic alliance created in 2001 including China, Kazakhstan, Kyrgyzstan, Russia, Tajikistan, Uzbekistan, India and Pakistan.

4. Regional Comprehensive Economic Partnership (RCEP) is a trade agreement signed in 2020 including the 10 ASEAN countries and Australia, China, India, Japan, South Korea and New Zealand.

\section{References}

Basken, P. (2020). Westerners sceptical of value of higher education - global poll. Times Higher Education, June 29.

Chomsky, N. (2019). Internationalism or Extinction. Routledge.

Chomsky, N. (2020). Shaping a humane world: Higher education perspectives. STAR Lecture for the Society of Transnational Academic Researchers Scholars Network Conference. December 8, 2020. 
Clark, B.R. (ed.) (1984). Perspectives on Higher Education: Eight Disciplinary and Comparative Views. Los Angeles: University of California Press.

Daenekindt, S., \& Huisman, J. (2020). Mapping the scattered field of research on higher education: A correlated topic model of 17,000 articles, 1991-2018. Higher Education, 80(3), 571-587.

Damme, D. van, \& van der Wende, M.C. (2018). Global higher education governance. In: B. Cantwell, H. Coates, and R. King (eds.) Handbook on the Politics of Higher Education. Edward Elgar Publishing, pp. 91-114.

Dorling, D. (2020). Slowdown: The End of the Great Acceleration - And Why It's Good for the Planet, the Economy, and Our Lives. Yale University Press.

Elken, M., \& Vukasovic, M. (2019). The looseness of loose coupling: The use and misuse of "loose coupling" in higher education research, In: J. Huisman, and M. Tight (eds.) Theory and Method in Higher Education Research, volume 5. Emerald, pp. 53-71.

Harari, Y.N. (2020). The world after coronavirus. Financial Times, March 20.

Horta, H., \& Jung, J. (2014). Higher education research in Asia: An archipelago, two continents or merely atomization? Higher Education, 68, 117-134.

Lewin, K. (1945). The Research Center for Group Dynamics at Massachusetts Institute of Technology. Sociometry, 8(2), 126-136.

Macfarlane, B. (2012). The higher education research archipelago. Higher Education Research \& Development, 31(1), 129-131.

Marginson, S. (2021). Heterogeneous systems and common objects: The relation between global and national science. CGHE Special Report.

Milanovic, B. (2016). Global Inequality: A New Approach for the Age of Globalization. Harvard University Press.

Newfield, C. (2021). Do contemporary societies need universities? Notes on higher education after the knowledge economy. Seminar 183. Centre for Global Higher Education. January 28.

Sachsenmaier, D. (2020). The humanities and the new Silk Road. In: Marijk van der Wende, William C. Kirby, Nian Cai Liu, and Simon Marginson (eds.) China and Europe on the New Silk Road: Connecting Universities Across Eurasia. Oxford University Press, pp. 296-312.

Sandel, M.J. (2020). The Tyranny of Merit: What's Become of the Common Good? Allen Lane.

Snow, C.P., \& Snow, B. (1959). The Two Cultures and the Scientific Revolution (Vol. 960). Cambridge University Press.

Stiglitz, J. (2020). Conquering the great divide. COVID-19 and Global Inequality. Finance \& Development, Fall 2020 Issue. International Monetary Fund.

Teichler, U. (2000). Higher education research and its institutional basis. In: S. Schwarz, and U. Teichler (eds.) The Institutional Basis of Higher Education Research. Kluwer, pp. 13-24.

Tight, M. (2013). Discipline and methodology in higher education research. Higher Education Research \& Development, 32(1), 136-151.

Tight, M. (2018). Higher education journals: Their characteristics and contribution. Higher Education Research \& Development, 37(1), 607-619.

Tight, M. (2020). Higher education: discipline or field of study? Tertiary Education and Management, 26, 415-428.

UNESCO (2015). Rethinking Education. Towards a Global Common Good? UNESCO.

Vlegels, J., \& Huisman, J. (2020). The emergence of the higher education research field (1976-2018): Preferential attachment, smallworldness and fragmentation in its collaboration networks. Higher Education, https://doi.org/10.1007/s10734-020-00600-8 
Wende, M.C. van der (2017). Reframing universities' global engagement for an open society. In: Austrian Council for Research and Technology Development (ed.) Prospects and Future and Tasks of Universities: Digitalization Internationalization - Differentiation. LIT Verlag Vienna, pp. 259-273.

Wende, M.C. van der (2020). Higher Education Research: Mapping the Field. HER Lecture, Utrecht Uiversity, 2 March, 2020.

Wende, M.C. van der (2021). Neo-nationalism, the Europe Union and universities. In: J. Douglass (ed.) Neo-Nationalism and Universities: Global Perspectives on Politics and Policy and the Future of Higher Education. Johns Hopkins University Press, pp. 117-140. 